Quite recently the Pax. Britannica has been extended completely round Kenia, though a portion of the route traversed by Hutchins and Ross was through country ranked until then as hostile, that is to say, the Mwèru country, lying on the eastern side of Kenia. A special escort was provided, and no hostility of any kind was expcrienced. The route followed comprised a journey com pletely round Kenia, and almost the whole time in the Alpine region at an elevation of about 12,000 feet. Two months was spent in the journey round Kenia. The object of the expedition was to ascertain the exact extent and value of the great forest girdle which stretches round Kenia. For this purpose it was found most convenient to travel at an altitude of about 12,000 feet in order to avoid the tussock grass, which extends above the upper forest limit, and is a serious impediment to progress in the open Alpine country. The tussock grass of Kenia grows in bunches 3 feet or 4 feet high and 3 feet or 4 feet through, and when, in the wet season, it is covered with half-frozen rain and hail, progress through it is not easy. Above the tussock is a zone of shorter grass, with a sufficient supply of firewood in the trunks of the giant heath. This tree, Erica arborea, marks the upper limit of tree growth on the Kenia Mountain.

Four glacicrs on the western side were visited, and found much as described in Mr. Mackinder's account of their condition nine years ago. Scenes of extraordinary Alpine beauty were traversed, and Mr. Ross obtained a series of photographs, which it is hoped may soon be published. $\mathrm{He}$ had charge of the triangulation which determined the boundaries of the forest, and he traversed all but a small portion of the Alpine region.

A number of weather observations were made, the chief feature of which was a persistent high-level north-east current at an altitude of about 20,000 feet. On Kenia Mountain, between elevations of 7000 feet and 14,000 feet, the atmosphere was singularly calm and serene. The general air movement was towards the central snowy peak by day and off it by night, exactly the reverse of what one would have expected in the case of a cool, damp, forest-clad mountain surrounded by dry, sun-scorched plains. Below 7000 feet elevation, and on the plains away from the mountain, the south-east trade wind blew strongly by day from the south and east. On the northern highlands, at about 10,000 feet elevation, the climate was curiously mild and equable. It was not only pleasant and healthful, but extraordinarily exhilarating. There was little or no frost at night, and the small quantity of rain that fell came mostly at night, while by day the equatorial sun was almost invariably screened by a thick mantle of cloud. This great uninhabited plateau, so singularly beautiful, so eminently a white man's country, suggests itself naturally as the site for the future capital city of the British possessions in mid-Africa-the Bogota of the Old World!

The whole of the Kenia Alpine region is healthful and invigorating, but there is a great contrast, during at least half the year, between the wet and misty southern slopes of Kenia and the dry, bracing plateau country of northern Kenia. The expedition consisted of three white men and about fifty natives, and, with the exception of a few cases of lung trouble among the coast natives, there was no sickness, in spite of hardships which, in a less favourable climate, would have told immediately. Hail was experienced on numerous occasions; in fact, on the wetter southern side of the mountain there was a severe hailstorm daily. A real snowstorm was experienced on one occasion only. Then the snow fell in light flakes exactly like a snowstorm in extra-tropical latitudes. This snowstorm lasted for some hours. For some miles, too, around the glaciers a light mantle of snow covered the ground, but this rapidly melted under the influence of a little sun and the warmer air which was experienced at higher altitudes during the day. Kenia peak was bare of snow on the north-eastern side, presumably on account of this comparatively warm upper current. These observations have a peculiar value, since they were made at the wettest time of the year-April, May, and June. The weather on the southern side of Kenia was at this season a striking contrast to what Mackinder and Hausberg experienced.
During the wet season, April and. May, Hutchins and Ross found the southern side at Alpine altitudes dripping with moisture, and the air nearly saturated with moisture the greater portion of the time. There was a small portion of the southern side of the mountain which was too wet for the upper traverse, and the forest there had to be inspected and mapped from below only.

Everywhere else the forest was examined from above and below, and linear sample areas of the timber measured. The forest belt that encircles Kenia had been reported to be interrupted on the northern side. This was found not to be the case. It is practically continuous right round Kenia. There is, indeed, a small break on the north-west side, but so small as to be scarcely worth mentioning. This break was barely eight miles long, little more, in fact, than the average width of the forest belt, which was found to vary from six to nine miles in breadth. On the northern and western sides, where the forest belt was thinnest, the quality of the forest was the best, it being there largely composed of cedar, which is found in the drier forest only. In the magnificent reach of forest filling up the great south-eastern bay of Kenia, Ibean camphor was abundant, but here cedar is entirely absent, and the effective thickness of the forest belt on this side is reduced by a broad sttip of bamboo, Arundinaria alpina. In the drier parts of the mountain the bamboo belt is much reduced in breadth; it is frequently broken, and sometimes absent.

The most valuable timbers in the Kenia forest are Ibean camphor on the wet south-eastern side, and cedar, Juniperus procera, on the drier western and northern sides. The former is no doubt a timber of exceptional value. Its botanical name has not yet been determined, its flower being now seen for the first time; but cedar is a loftier and far more abundant tree than camphor. It runs up in straight stems to heights of more than 100 feet, and a tree was measured (on northern Kenia) with a diameter of nearly I2 feet. It is extremely durable, and the forest was found richly stored, not only with the live timber of to-day, but with the dry and still sound timber of past ages. Fire does incalculable damage in these cedar forests. The most abundant timber in the Kenia forest is yellowwood, Podocarpus thunbergii, var. milanjianus, a tree differing little from the widespread and well-known yellowwood of South Africa. Another yellow-wood, Podocarpus gracilior, in stature and shape has been compared to the Kauri of New Zealand, but this yellow-wood is but sparingly represented. The finest timber is in the great south-eastern Bay of Kenia, but this is largely composed of hardwoods, which have not the same value as the camphor, and conifers. Altogether the expedition disclosed a forest of great value, and a particularly important asset to a young country such as British East Africa, without mineral wealth.

\section{THE INTERNATIONAL FISHERY CONGRESS AT WASHINGTON}

THE fourth International Fishery Congress, which met in Washington on September 22, and adjourned sine die on September 25, is generally conceded to compare well with the high standards set by its predecessors in Paris, St. Petersburg, and Vienna. Although several of the more important fishery nations were not represented, the membership was truly international. About twenty foreign countries of Europe, Asia, North and South America, and Australasia were in attendance through delegates of Governments, scientific bodies, and fishery societies, and practically all the States of the United States wore officially represented. Although the place of meeting and the preponderance of American membership tended to accentuate the American point of view, the strength and ability of the foreign delegation gave to the proceedings a catholicity of expression not always observable in international congresses.

The international regulations of the fisheries on the high seas was the subject of considerable discussion, three papers having that title being presented, respectively, by Mr. Fryer and Dr. Olsen, of England, and Mr. Stevenson, of Washington. 
The recognition of the freedom of the seas by the stronger maritime Powers has been slow and grudging, and the crystallisation of the now recognised distinctions between international and territorial waters has been the growth of comparatively recent years. The conventions which have been entered into between nations respecting the regulation of the fisheries common to the subjects of the contracting parties have been surprisingly few considering the importance of the interests involved, though this is not surprising to those in a position to appreciate the biological, legal, and practical difficulties presented for solution.

These international fishery regulations fall into two classes, the one for the conservation of the resources of the sea, the other for the maintenance of order and the protection of life and property. Concerning the necessity for the latter there was not much difference of opinion, and, in fact, most of the accomplished fishery conventions between nations have been for these purposes. That the resources of the sea are in actual need of conservation through international agreement or the concurrent action of the maritime nations was by no means clear to many who took part in the discussion, though most were agreed that the fisheries for sessile organisms, such as sponges, corals and pearl oysters, or for whales, seals, and other marine mammals, were doomed unless means can be devised for the extension of protective measures beyond the present recognised limits of territorial jurisdiction.

It was contended with considerable force that in the case of sessile organisms (as distinguished from feræ naturæ) susceptible of culture involving actual occupation of the bottom, not only justice, but necessity, demands the extension of a restricted form of property right beyond the marine league from shore. The requirements of man have outrun the bounty of nature, and the barren bottoms covered by the high seas should no longer be permitted to go to waste. In other words, it was held that the present and future needs of mankind demand the extension to certain international waters of the measures which experience has shown to be necessary for the edible oyster within territorial limits.

The recent convention between the United Kingdom and the United States, looking to the enactment of concurrent legislation for the control of the fisheries in waters contiguous to the United States and Canada, was referred to with approval by speakers from both countries interested, and among the American participants in the discussion there was a surprising unanimity favouring Federal control of the fisheries in inter-State waters now subject to several State regulations.

In the field of aquiculture two very important papers were submitted by Prof. A. D. Mead. The first was a description of an apparatus for hatching, rearing, and transporting fishes and other aquatic animals. In this the great departure from former methods is that the hatchery is taken to the water rather than the water to the hatchery. It " consists essentially of creating and maintaining within an enclosure of 'native' water a gentle upward, swirling current" by means of propellers revolved through the medium of suitable gearing by a gasoline engine or other motor. The rotary currents set up by the propellers aërate the water, eliminate the toxic gases of respiration, and prevent the suffocation of the eggs and larvæ by their massing on the bottom and sides or through the deposit of sediment. For hatching and rearing the compartments or units, about ro feet square, are mounted on suitable floats surrounded by the open natural waters, which maintain the cars at an equable optimum temperature. For transporting fishes the same principle is applied to receptacles packed in ice.

Prof. Mead's second paper was an exposition of the use of this apparatus in hatching and rearing lobsters. The artificial hatching of these crustaceans presents few difficulties, but, on the other hand, it possesses no very great advantage over the natural method. The heaviest mortality in this species is in the period of three or four weeks between the emergence of the young from the egg and the period when it assumes its bottom habit. During this time the larvæ are helpless and exposed to many enemies, and Dr. Mead's method is the only one yet proposed which permits the young to be reared to a stage where they can care effectively for themselves. Equally good results can be attained with various fishes passing through similar critical stages, and fish culturists now have in their possession an entirely new and simple method, not only for hatching fishes, but for economically rearing them in large numbers to an age when they can care for themselves. The method is a wide departure from those previously employed, and marks the greatest advance in fish culture within recent years. It may be added that it has for several years demonstrated its practical utility.

The "lobster question" in general provoked considerable debate, in which English, Canadian, and American representatives participated. Dr. Geo. W. Field proposed a radical departure in the regulation of this fishery, advocating the use of apparatus which will automatically exclude the large breeding lobsters from capture, while taking those between 9 inches and $x_{I}$ inches in length, which produce few or no eggs. This proposal was strongly combated, especially by the advocates of artificial hatching, who contended that present methods are now resulting in an increase in the lobster catch, and that a change would prove disastrous.

Three papers by Messrs. Paul Reighard, Frank N. Clark, and S. W. Downing, on the subject of the promotion of white-fish production in the Great Lakes, while dealing with a fishery in which the United States and Canada only are concerned, precipitated a discussion of international interest. The three writers, reasoning along somewhat different lines, all reached the conclusion that artificial propagation offers the only feasible plan for increasing the white fish; that a close season during the spawning period is worse than futile, especially where there are offered facilities for taking and hatching eggs; and that closed seasons and restrictive measures should not be applied to the spawning fish, but to small and immature specimens. These propositions, while representing the preponderance of American opinion on the subject, met with vigorous opposition from Mr. Chas. E. Foyer, of England, and from several American delegates, while Prof. E. E. Prince, of Canada, doubted the practical feasibility of preventing the capture of small fish if fishing were permitted at all.

Dr. P. P. C. Hoek, of the Netherlands, presented a paper on the propagation and protection of the Rhine salmon. The Rhine is distinguished among the salmon streams of the Atlantic basin by its productiveness, and Dr. Hoek demonstrated that, as under existing conditions comparatively few salmon reach their natural spawning grounds, the present supply of fish is maintained principally by artificial propagation. To be effective, however, this must adhere in many particulars as closely as possible to nature's method; especially must the fry be planted in these upper waters in which the proper conditions exist for their year-long stay in fresh water. The loss sustained in the long downward run to sea must be compensated for by more extensive planting in the headwaters.

Bearing upon this question of the utility of fish culture, an interesting paper was presented by Mr. L. G. Ayson, of New Zealand, on the introduction of American fishes into New Zealand waters. New Zealand, though bountifully provided with rivers and lakes, presents the extraordinary characteristic of an almost total lack of freshwater commercial and sporting fishes. About twenty-five years ago three consignments of eggs of the steelhead trout, Salmo gairdneri, were planted, and the species artificially propagated, with the result that to-day they exist in extraordinary numbers in nearly all streams and lakes in the northern part of the country. The Chinook salmon, Oncorhynchus tscharytscha, was planted between 1901 and 1907, about two million eggs being imported. The first returns were in 1905 , when a few were caught by anglers, and as there has been a spawning run each year since, it is believed that the species is now firmly established. Several other American fishes have been introduced into the waters of New Zealand, where they have become thoroughly acclimatised. The results of planting certain American Salmonidæ in Europe are well known, and recent experiments in carrying them to Argentine have been favourably reported on. Experiments in the acclimatisation of fishes, however, have not 
always met with success. Certain lakes possessing all the obvious biological and physical requirements have been repeatedly planted without result, and it has been but recently determined, through the work of Prof. E. A. Birge, that the failure is due to peculiarities of the gaseous content of the water. In a paper on the gases dissolved in the waters of Wisconsin lakes, Dr. Birge illustrated his studies, which are of the highest value to fish culture.

A paper on the utilisation of sea-mussels and dogfish as food, presented by Dr. Irving A. Field, opened a very general discussion on a subject which appealed to both the biologists and the practical fishermen. During recent years the horned dogfish (Squalus acanthias) has been extremely destructive to fish and fishing on the coasts of Canada and New England, while the smooth dogfish (Mustelus canis) is a perennial menace to the lobster. In Canada oil and fertiliser works have been established for the purpose of supplying a market and encouraging the destruction of the dogfish, and Prof. Prince is of the opinion that they have to some measure decreased in numbers.

Dr. Field's experiments have demonstrated that the smooth dogfish, salted and dried, makes a product closely resembling the cod, and in a fresh condition it is not inferior to texture and flavour to halibut; the horned dogfish, being more oily, is better adapted for tinning. Mr. Fryer stated that the equally destructive dogfish of the English coasts had been placed on the markets by the fishermen, and while it was unobjectionable as to quality, it met with preiudice on account of its name, a difficulty which also confronts the exploitation of dogfish as food in the United States and Canada. An euphonious name, not deceptive in character, would assist greatly in converting a fishery menace into a valuable product and important source of cheap food supply. The practical difficulties confronting the utilisation of these fish are being made the subject of inquiry by various technical bodies in the United States and Canada.

A communication from the Rhode Island Commission of Inland Fisheries, in reference to the effects of gunfire on schools of fishes, developed a difference of opinion between the scientific men and the practical fishermen. The latter declared that the heavy detonations from cannon drive the fish away from the coast, but the results of experiments at Woods Hole, as recounted by Dr. Sumner, indicated that mackerel and other surface-living fishes were but little disturbed by either gun-fire or the noises made by boats using explosive engines. The investigations of Dr. Parker at the fisheries laboratory prove that certain fishes are influenced by sound stimuli as distinguished from the grosser mechanical vibrations of the water, but that their sudden movements of alarm are dictated by sight rather than by hearing.

Eighteen corporations and individuals interested in the fisheries offered prizes for contributions on special subjects, and of these seven were unawarded, either because the papers submitted did not satisfy the strict conditions of the award or because they did not conform to the standard of merit imposed by the international jury of awards. Two awards were made to Prof. A. D. Mead for the papers above-mentioned, two to Dr. H. F. Moore for papers on the sponge fisheries and on growing sponges from cuttings, one to Mr. Dwight Franklin for the best method of preparing fishes for museum purposes, one was divided between Dr. F. A. Lucas and Mr. R. W. Minor, for papers on the best plan for an educational exhibit of fishes, one was given to $\mathrm{Mr}$. Chas. H. Stevenson for the paper above alluded to, one to Mr. Paul Reighard for the best plan to promote the white-fish production of the Great Lakes, one to Prof. Jacob Reighard for the best methods of observing the habits and recording the lifehistories of fishes, one to Mr. Chas. G. Atkins for a paper on foods for use in rearing young salmonoids, and one to Mr. John J. Solomon for a process for preserving the pearl fisheries and increasing the yield of pearls.

Many papers of much practical and scientific merit were submitted, but not read for lack of time, but they will be published in the proceedings of the congress. The fifth congress will be held in Rome in Igrx, the year of the semi-centennial of the Italian Federation.

NO. 2039, vOL. 79]
PSYCHOLOGY OF PLEASURE AND PAIN.

THE last two numbers of the Psychological Review (July and September) have contained important articles by Prof. Max Meyer, of the University of Missouri, on the nervous correlate of pleasantness and unpleasantness. In the former the author brings out the contradictory character of the present views of psychologists on this subject, and in the latter proposes a theory that he believes accords with all known facts and gives proportionate weight to the various aspects of the question upon which his predecessors have dwelt too exclusively. The clearest opposition has hitherto been between the psychologists, who hold that pleasantness and unpleasantness are merely weak (and therefore badly localised or entirely unlocalised) forms of the sensations, which at a higher degree of intensity become respectively sexual sensation and pain, and those who, denying their substantive status, regard them merely as aspects or "tones" of sensational processes.

Prof. Meyer's theory is of a different type altogether, and is based upon the concept of an hierarchy of reflex arcs or a "centralisation by degrees." Let A and B be two sensori-motor systems of neurons relatively independent, but having at least one connecting neuron in common. It is always possible for these to merge into a more complex sensori-motor system, C. The marks of this higher organisation will be (I) that stimulation of a sensory point of either A or B may produce simultaneous reactions at motor points both of $\mathrm{A}$ and $\mathrm{B}$; and (2) that simultaneous stimulation of sensory points of both $\mathrm{A}$ and $\mathrm{B}$ may produce a reaction at a motor point of $A$ or $B$ only. In the case of such a system, if the subsystem $\mathrm{A}$ is functioning a strong stimulation of subsystem $B$ will produce a decrease in the intensity of the current in A (drawing it off, in fact, towards motor points of B), while a gentle stimulation of $\mathrm{B}$ will merely increase the current setting towards motor points of $\mathrm{A}$. The decrease or increase in the flow through system $A$, due to the action of $B$, is the nervous event which will be experienced as unpleasantness or pleasantness respectively. For example, the slight degree of pain produced by scratching after an insect's bite is rather pleasant, for it actually increases the energy of the scratching process. If, however, the pain becomes too intense, its own typical reaction is set up; energy is drawn off from the scratching process, and unpleasantness is felt.

It follows on this theory that pleasantness and unpleasantness are attributes of the relatively more complex psychophysical functions, and, therefore, that their highest intensity may be expected to accompany intellectual activity-a result which the author claims as a powerful piece of evidence of the superiority of his doctrine over that which would regard them as "feeling tones" of sensations.

\section{SCIENTIFIC EDUCATION OF NAVAL ARCHITECTS.}

I $\mathrm{T}$ has occurred to me that an appropriate subject for the address, which it is my duty to deliver as chairman of the council, may be found in a brief account of the methods adopted for the education of naval architects: in this country during the past century. I venture to hope that, apart from its particular interest for those engaged in shipbuilding, the narrative may have some value and attraction for those interested in technical education generally, and that it may throw some light on problems of higher technical education which still await solution in this country.

In I806 the Commission of Naval Revision reported in regard to the principal shipbuilding officers of the Royal Navy. There is evidence that outside the Admiralty service the standard of professional attainment amongst British shipbuilders was then low. As practical ship-carpenters they excelled; their ships were "well and truly built," strong and durable. As ship-designers they depended on

1 From an address delivered before the Socicty of Arts on November is bv Sir W. H. White, K.C.B., F.R.S., chairman of the Council of the Society. 